\title{
Study efforts, learning strategies and test anxiety when striving for language competence: the role of utility value, self-efficacy, and reasons for learning English
}

\author{
Ayça Üner ${ }^{\mathrm{a}}$ (D), Athanasios Mouratidis ${ }^{\mathrm{b}}$ (D) and ilker Kalender ${ }^{\mathrm{c}}$ (D) \\ ${ }^{a}$ Bilkent University English Language Preparatory Program, Bilkent University, Ankara, Turkey; \\ ${ }^{\mathrm{b}}$ Department of Psychology, Bilkent University, Ankara, Turkey; 'Graduate School of Education, \\ Bilkent University, Ankara, Turkey
}

\begin{abstract}
Previous research has shown that utility value and expectancy for success, as well as the reasons for academic striving, could partly explain academic engagement. Yet, their joint role in predicting learning strategies and test anxiety has not been thoroughly understood, especially in contexts where pressure for success is high. We examined this issue in a sample of Turkish university students who were attending a language preparatory school $\left(N=1009 ; 53 \%\right.$ males, $M_{\text {age }}=19.14$ years; $\left.S D=1.08\right)$ and were under the psychological pressure to pass their qualifying exams. Regression analyses showed that next to self-efficacy beliefs, it was intrinsic reasons which positively and consistently predicted learning strategies; in contrast, self-worth concerns positively predicted test anxiety. These relations emerged even among students who experienced failure and were thus psychologically pressed to succeed. Our findings suggest that intrinsic reasons for academic striving might play a decisive role even in psychologically pressuring contexts.
\end{abstract}

\section{ARTICLE HISTORY}

Received 10 December 2018

Accepted 26 February 2020

\section{KEYWORDS}

Utility value; self-efficacy beliefs; intrinsic reasons; self-worth concerns;

learning strategies

Learning a second language requires effort, discipline, and effective learning strategies (Dörnyei, 2002). Around the non-English speaking world, universities, which offer courses in English language, require their students either to prove their fluency in English, or to attend a set of short-term, intensive, and highly demanding English-language courses in a preparatory programme in their first year of education as undergraduate students. Attending such a programme requires not only extra fees but also effective learning strategies to pass the challenging qualification exams. If students cannot pass these exams, they need to repeat the coursework and re-take the exams until they succeed, while repeated failure to pass these exams may result in dismissal. Understandably, students in such preparatory programmes are put under extreme psychological pressure. 
Given that academic success relies heavily on effective learning strategies such as proper effort regulation and use of critical thinking (Credé \& Phillips, 2011), the question is which motivational variables in such demanding contexts where pressure for success culminates could explain why some students put more effort in their studies, use more effective strategies, and experience less test anxiety than others. Is it only a matter of how much students value their academic tasks? Or should we also consider other reasons? In this cross-sectional study, we used a mixed-method research design to show, first, through qualitative analyses that students in preparatory educational contexts may experience excessive psychological pressure to succeed and second through quantitative analyses to investigate to what extent in such pressuring contexts valuing class activities (i.e. utility value) and believing in one's competence (i.e. self-efficacy beliefs) relate to effort regulation, test anxiety, surface-level learning strategy (such as rehearsal which refers to naming, reciting, and memorising information) and deep-level learning strategies (such as critical thinking and meta-cognitive selfregulation). Critical thinking reflects students' propensity to engage in reading with reflective Scepticism focussed on deciding what to take for granted and what not (Halonen, 1995) and metacognitive self-regulation refers to students' capacity to plan and monitor their learning strategies (Pintrich \& Garcia, 1991). We opted for these strategies as research has shown that they can all function as proxy for academic success (Richardson et al., 2012).

Further, by relying also on Self-Determination Theory (SDT; Ryan \& Deci, 2017), a meta-theory which outlines, among others, the different reasons for which students may engage in an activity and the implications that these reasons can have in their performance and well-being, we also examined whether intrinsic reasons (such as challenge-seeking) or self-worth concerns (which reflect psychologically controlling reasons, according to SDT) would explain additional variance in students' effort regulation, learning strategies, and test anxiety. More importantly, we examined these patterns of associations in a sample of students who appear to be psychologically pressured to succeed, with some of these students being especially stressed because they had failed the qualification exams at least once before and were, therefore, repeating their preparatory classes. In that way, we tested in a psychologically pressuring context one of the pillars of SDT (Ryan \& Deci, 2017). In particular, we examined whether it is indeed the intrinsic reasons rather than the usefulness (i.e. utility value) or the psychologically pressuring reasons (such as self-worth concerns) which more reliably relate to effective learning strategies.

\section{Utility value and self-efficacy beliefs in education}

According to the expectancy-value framework, the degree to which learner engage in an activity depends on their expectancies for success and on the subjective, usefulness (i.e. utility value) of that task (Eccles \& Wigfield, 2002). Research has pointed out that the more students find tasks useful for some future purpose and the more they believe in their ability to successfully carry out the assigned learning activities, the better they regulate their study efforts (Eccles \& Wigfield, 2002). Indeed, a number of studies have shown that utility value and self-efficacy beliefs (Bonaccio \& Reeve, 2010; 
Roick \& Ringeisen, 2017) are positively related with a host of desired outcomes, such as less test anxiety (Chou, 2018; Drysdale \& McBeath, 2018; Zimmerman, 2000) and more effort regulation (Bathgate \& Schunn, 2017; Credé \& Phillips, 2011), and deeplevel learning strategies such as critical thinking (Liem et al., 2008), and meta-cognitive strategies (Komarraju \& Nadler, 2013).

Notably, however, some reports have revealed that valuing tasks are associated with both deep-level learning strategies and surface-level ones such as rehearsal. For instance, Komarraju and Nadler (2013) found utility value to relate positively not only to elaboration and critical thinking but also to rehearsal. Relevant to the focus of the present study, several studies have revealed a similar pattern within the context of learning a second language. For instance, Liem et al. (2008) found positive relations of task value to both surface-level and deep-level learning strategies among East Asian adolescent students. Most likely, such positive relations may be due to the dual meaning-namely, intrinsic versus extrinsic-that a task may carry for a learner (Lens et al., 2002). To illustrate, while some students may ascribe an intrinsic value to learning English (e.g. because it is challenging to learn new things), some others may only bestow an extrinsic reason for learning the same topic (e.g. to prove their worth to significant others who might question their commitment).

This distinction has been delineated by SDT (Ryan \& Deci, 2017) according to which students may engage in activities either due to autonomous or controlled reasons. Autonomous reasons reflect more self-determined behaviours that student undertake because they find them challenging, or interesting (intrinsic motivation) or personally important (identified regulation). In contrast, controlling reasons reflect less self-determined behaviours that student carry out, either due to some external psychologically pressuring reasons such as to attain a promised reward, to avoid some negative implications (external regulation), or due to some internal psychological pressuring reasons such as to avoid feelings of guilt or to boost (or maintain) their selfworth (introjected regulation). Research has shown that autonomous (in which intrinsic reasons are included) as compared to controlling reasons (in which self-worth concerns are included) are associated with effective learning strategies, such as study efforts (Mouratidis et al., 2018) and critical thinking (León et al., 2015).

A question that needs to be answered thus is whether studying for intrinsic reasons still hold true in contexts where the pressure for success-or for not failing again-is high. As a qualitative study has recently revealed, among the most common stressors that put extra burden to university students are the pressure to perform well and financial concerns (Hill et al., 2018). These two factors are directly relevant to our study, given that poor performance may result in repeating a class and thus put extra financial burden to one's family and ultimately to the very same student. Such pressure is not only likely to give rise to potential threats of appearing incompetent (Folkman et al., 1986), but also to burnout, academic withdrawal, and eventually, academic underachievement (Tuominen-Soini \& Salmela-Aro, 2014), which in turn may result in even more stress, leading students to a downward spiral from which they can barely escape.

We, therefore, aim to examine whether in such demanding and heavily taxing contexts, utility value and self-efficacy would remain robust predictors of effective learning 
strategies or whether intrinsic reasons for task engagement versus reasons for studying to prove one's self-worth could explain students' effective learning strategies.

\section{Intrinsic reasons and self-worth concerns in education}

Students who study for intrinsic reasons-for instance, those who are seeking challenge-are more committed (Vansteenkiste et al., 2010) and perform better academically (Lepper et al., 2005) than those who study for psychologically controlling reasons, such as to please significant others or to prove their self-worth. According to SDT, such self-worth concerns interfere with one's learning efforts because much effort is directed inwards, towards self-evaluation, rather than to the task itself (Ryan \& Deci, 2017), resulting in less persistence (Noels et al., 2000; Pintrich, 2000).

Research based on the achievement goal perspective (Elliot, 2005), such as that conducted by Dompnier et al. (2009), has pointed out that even when students strive for mastery they may do so for social desirability (e.g. to garner teachers' appreciation) and in doing so, they perform worse than students who simply strive to succeed. Along similar lines, some other studies (e.g. Michou, et al., 2014) have shown that pursuing a learning goal for psychologically controlling reasons as compared to intrinsic ones are associated with poorer learning outcomes, including over-reliance on surface level learning strategies, decreased persistence, and higher test anxiety (see also Vansteenkiste et al., 2010).

Taken together, both the SDT (Ryan \& Deci, 2017) and the achievement goal perspective (Elliot, 2005) suggest that the intrinsic reasons versus self-worth concerns may further explain why students who may hold the same utility value and self-efficacy beliefs for their studies may differ in effort regulation, learning strategies, and test anxiety.

\section{The present research}

This study took place within a context, characterised by excessive psychological pressure to succeed (or not fail again). To test our hypotheses, we recruited a sample of Turkish university students who were studying English language at a preparatory school in a large university. The preparatory school offers English language courses at various levels, and students have to successfully pass high-stake exams before they are admitted to their respective departments. The students could be classified into three groups: those who never failed in the exams up to the day of data collection and thus never repeated any level ('non-repeaters'); those who had failed once or more times in one or more of the past trimesters ('past-repeaters'), and those who failed once or more times in current trimester ('current-repeaters').

We focussed on a set of markers that are closely associated with academic learning and success. These included effort regulation (as an index of students' study efforts), rehearsal (as an index of surface-level strategies), critical thinking and meta-cognitive self-regulation (as indices of deep-level learning strategies) and test anxiety as an affective response in an academic testing situation (Richardson et al., 2012). Given that students may learn for different reasons (Dompnier et al., 2009; Vansteenkiste et al., 
2014), we included intrinsic reasons and self-worth concerns as additional predictors of academic achievement. We examined through a series of hierarchical regression analyses to what extent intrinsic reasons and self-worth concerns would explain, over and above utility value and self-efficacy, variation in the studied correlates.

Along with the quantitative approach, we also gathered qualitative data through semi-structured interviews with a focus group of $n=15$ students. The qualitative part of the study mainly served to examine whether students were indeed experiencing psychological pressure to succeed in the preparatory school exams. We assumed that this pressure would escalate among those who failed at the current level. We were particularly interested in examining whether utility value and self-efficacy beliefs, as well as intrinsic reasons and self-worth concerns would still predict learning strategies and affective concerns and remain invariant across the three groups. Showing that the patterns of associations would remain similar across all three groups would further underscore the key role that intrinsic reasons and self-worth concerns can play in such contexts.

Based on prior research findings (e.g. Pintrich \& De Groot, 1990), we hypothesised that both utility value and self-efficacy would relate positively to effort regulation, rehearsal critical thinking, and meta-cognitive self-regulation. Also, we anticipated that utility value would relate positively to test anxiety, as the more students ascribe value to their learning tasks, the more resources they invest, something, however, which might come also with a sort of psychological cost (e.g. test anxiety) (Garcia \& Pintrich, 1994). We also expected a negative relation between self-efficacy and test anxiety, given that students with low self-efficacy are more likely to experience increased anxiety (Putwain \& Daly, 2013).

Moreover, in line with self-determination theory which states that intrinsic reasons versus self-worth concerns relate to better learning strategies (Ryan \& Deci, 2017), we expected intrinsic reasons to especially relate positively to critical thinking. We also hypothesised that self-worth concerns would relate positively to effort regulation, rehearsal and test anxiety, signifying high quantity, but not high quality of motivation (Ryan \& Deci, 2017). We further hypothesised that these relations would remain invariant across students with different histories (i.e. non-repeaters, past-repeaters, and current-repeaters) in terms of success versus failure in prior exams.

\section{Method}

\section{Participants and procedures}

Participants were 1009 (476 females, $M_{\text {age }}=19.14$ years; $S D=1.08$ ) university-level students studying at different levels (e.g. pre-intermediate, intermediate, and upperintermediate) in the preparatory school of a university located in Ankara, Turkey. After obtaining an approval from both university and preparatory programme ethics committees, the lead author held a short meeting with instructors to explain the purpose of the research. Upon their consent, the instructors distributed the questionnaires, along with a cover letter and an informed consent form to be filled in by the participants. The instructors emphasised that participation was voluntary, and responses 
would be kept anonymous and confidential. Only those students who signed the informed consent participated in the study.

\section{Semi-structured Interviews}

In our attempt to investigate students' perception regarding their success and failure in their language learning progress, we invited 18 students with varying status ranging from no repetition to six times of repetition, to be interviewed. Fifteen students accepted to take part in the study, with five of them never repeating a level before (non-repeaters), five having repeated a level before (past-repeaters) and five repeating the current level (current-repeaters). More information about each interviewee and the number of times each of them had repeated, if so, a certain level can be found at the online Supplementary material (Table S1)

We used a set of questions to learn the degree to which they experience psychological pressure to succeed in (or not to fail again) their forthcoming exams. Some questions referred to their motivation (e.g. 'Why are you studying [this particular discipline]? Why it is important to you?'). Some other questions referred to their learning strategies ('What strategies do you use to learn the lesson?'), and a few of them to the stress they may experience (e.g. 'Do you feel anxious when you take exams?'; 'To what factors might you attribute your failure?').

\section{Measures}

All the items that refer to the quantitative part of the study were presented on a seven-point Likert type format $(1=$ Not at all true of me; $7=$ Totally true of me).

\section{Utility value}

Three items, taken from the task value subscale from MSLQ (Pintrich \& De Groot, 1990), were used to assess to what extent students valued their studies in the preparatory school. Although the original scale assessing task value in MSLQ consists of 6 items, we used only three (' I think I will be able to use what I learn in one level in other levels;' 'I am very interested in the content of this course', and 'I think the course material in this class is useful for me to learn') as indicators of utility value. We excluded the other items because they tapped into both utility value and intrinsic reasons for which one might value a task (e.g. 'Understanding the subject matter of my course is very important for me'; 'I like the subject matter of this course;' and 'It is important for me to learn the course material in this class'). A similar approach has been endorsed by other researchers (e.g. Durik \& Harackiewicz, 2007), assessing utility value separately from intrinsic task value. The Cronbach alpha for this three-item measure was satisfactory $(\alpha=0.68)$.

\section{Self-efficacy}

We used five items from the eight-item subscale of MSLQ to assess the degree to which the students felt that they had the capacity to successfully accomplish their 
studies in the preparatory school (e.g. 'I believe I will receive an excellent grade in this class'; $\alpha=0.84)$.

\section{Intrinsic reasons}

Two items that refer to challenge seeking, also taken from MSLQ, were used to assess whether students participated in the preparatory school for intrinsic reasons: 'In a class like this, I prefer course material that really challenges me so I can learn new things' and 'In my classes, I prefer course material that arouses my curiosity, even if it is difficult to learn'. $(\alpha=0.52)$.

\section{Self-worth concerns}

For the purposes of the present study, a single item from the extrinsic motivation subscale from MSLQ was used. The item was: 'I want to do well in my classes because it is important to show my ability to my family, friends, or others'. Content-wise, this item seems to reflect a psychological pressure to perform well for external, contingent-worth reasons. As such, it seems to differ from the other items that are also included in the extrinsic motivation subscale. The other items denote one's desire to get a good grade (i.e. 'Getting a good grade in this class is the most satisfying thing for me right now'), improve one's grade (i.e. 'The most important thing for me right now is improving my overall grade point average, so my main concern in this class is getting a good grade'), and outperform the others (i.e., If I can, I want to get better grades in this class than most of the other students'). As Grant and Dweck (2003) have shown (see also Vansteenkiste et al., 2014), these other items seem to tap into different constructs, rather than a single underlying extrinsic construct. In line with this recent reasoning, we opted for keeping only the item that best reflected the reality encountered by the participants of the present study. A measurement model for a four-factor model, which was empirically identified for each latent variable (i.e. utility value, self-efficacy, intrinsic reasons and the single-item self-worth concerns), yielded acceptable fit: $S-B \chi^{2}(40, N=948)=133.50, p<.01, C F I=0.948$, SRMR $=0.043$, RMSEA $=0.050$ (90\%Cl: 0.042-0.058).

\section{Test anxiety}

The five items that refer to the degree to which the students felt stressed and anxious during exams were used from the MSLQ test anxiety scale (i.e. 'When I take tests I think of the consequences of failing'; $\alpha=0.78$ ).

\section{Effort regulation}

The degree to which students put effort into their studies was assessed by means of the four items from MSLQ. A sample item reads: 'I work hard to do well in my classes even if I don't like what we are doing'. $(\alpha=0.60)$.

\section{Rehearsal}

Students answered four questions that refer to the degree to which they practice the material through memorisation of key information, implying the use of surface-level 
learning strategies (Pintrich \& Garcia, 1991). (e.g. 'I memorise key words to remind me of important concepts in my classes; $\alpha=0.73$ ).

\section{Critical thinking}

The five items from the MSLQ were used to assess whether students employ critical thinking, a deep-level learning strategy (Pintrich \& Garcia, 1991). An example item reads: 'I treat the course material as a starting point and try to develop my own ideas about it.' $(\alpha=0.79)$.

\section{Meta-cognitive self-regulation}

This subscale from MSLQ contains 12 items that measure the extent to which students plan learning strategies, monitor and regulate cognitive activities to accomplish learning goals (Pintrich \& Garcia, 1991). An example item reads: 'When reading for my courses, I make up questions to help focus my reading.' $(\alpha=0.81)$. The five-factor measurement model that included the five outcomes (i.e. effort regulation, rehearsal, critical thinking and test anxiety and metacognitive self-regulation) and where the errors of two items from effort regulation, critical thinking, test anxiety and metacognitive self-regulation were allowed to covary showed the following fit: $S-B \chi^{2}(285$, $N=858)=865.55, \quad p<.001, \quad \mathrm{CFI}=0.908, \quad \mathrm{SRMR}=0.061, \quad \mathrm{RMSEA}=0.049 \quad(90 \% \mathrm{Cl}$ : $0.045-0.052$ ). A composite score was created separately for each subscale by taking the average score of the respective items.

\section{Plan of analyses}

The analysis was conducted in three stages. The first stage included content analysis of the interview transcripts. The content analysis was done according to the general recommendations provided by Braun and Clarke (2006) and Creswell and Plano Clark (2007). Given our basic assumption, the high psychological pressure that the students experienced to succeed in (or not to fail) the forthcoming exams, we were interested in detecting through their own words whether this was indeed the case. Two independent coders, independently coded the transcripts, focussing on those phrases or answers that would signify the pressure the students felt they were experiencing due to highly demanding context.

The second stage included preliminary quantitative analysis, where we inspected the descriptive statistics and bivariate correlations for the full sample $(N=1009)$. The third stage, aiming at addressing our main research questions, comprised five hierarchical regression analyses (Cohen et al., 2003), one for each of the five dependent variables (i.e. effort regulation, rehearsal, critical thinking, meta-cognitive self-regulation, and test anxiety). In each regression model, we first regressed gender, utility value, and self-efficacy in Step 1. We were particularly interested in examining whether students' status (i.e. non-repeaters, past-repeaters, and current-repeaters) would explain any differences in the reported outcomes. Therefore, in Step 1, we also included students' status as predictors. Specifically, following the notation suggested by Cohen et al. (2003), we used non-repeaters as a reference group and through two dummy variables, one indicating past-repeaters group and the other the current-repeaters 
group we aimed to examine whether these two groups differed from non-repeaters. Next, we tested for the interaction between utility value and self-efficacy, as well as all the likely interactions between either utility value or self-efficacy and students' group status. In Step 2, we included intrinsic reasons and self-worth concerns, followed by the interaction between intrinsic reasons and self-worth concerns as well as all the likely interactions between either intrinsic reasons or self-worth concerns with students' group status. To properly test all the interactions, we centred all the first-order predictors (Cohen et al., 2003). These interactions enabled us to examine whether the relations would be homogeneous across the three different groups. When testing all the regression models, we set the alpha level at 0.01 to control for inflated Type I error (Bonferroni correction).

\section{Results}

\section{Content analyses}

In the first step, we tried to gauge to what extent the students from the focus group were experiencing psychological pressure. Following the guidelines suggested by Welbers et al. (2017), we employed a dictionary-approach method with the aid of the Quanteda package (Benoit et al., 2018) that is applicable through R Core Team (2018) statistical software. We tried to capture through students' own words whether they indeed felt a kind of pressure to succeed in or not to fail in the forthcoming exams. Specifically, we used the following stem words as tokens implying psychological pressure: fail, failing, failure, pressure, pressing, pressured, anxious, anxiety, stress, stressed, stressful, burden, fear, fearful, nervous, tense, tension, worry, worrisome, worrying, agony, conflict, conflictual, stretch, force and forced. Among the 2928 words that were derived from the transcripts, 37 of them were found to imply psychological pressure according to our dictionary-made approach. These statements were made by 12 out of the 15 interviewees (80.0\%). Each student referred on average more than two times to issues related to psychological pressure $(M=2.47$ statements; $S D=3.16$; observed range: $0-12$ ). Some characteristic statements are available online as a supplementary material and illustrate the psychological pressure that students were feeling to succeed (or not fail) in the upcoming exams.

Setting aside the dictionary approach, there were several other comments made by some students which reflected even more markedly the psychological pressure For instance, a student commented:

I think about my parents a lot. I say to myself I must study hard. My father doesn't say anything explicit, but I know I must work hard to pay them back. By being successful, I feel I can pay things back.

While another student stated:

When I wake up in the morning I see my mother. I see my mother. My mother looks like she is upset with me, but it is not really like that. I constantly ask her, "mom what happened?

Taken together, these qualitative analyses provide some evidence to our basic assumption that the studied environment was overtaxing for some students. The 
Table 1. Means (M) and standard deviations (SD) and bivariate correlations of the measured variables of the study.

\begin{tabular}{lccccccccccr}
\hline Variables & $M$ & $S D$ & 1 & 2 & 3 & 4 & 5 & 6 & 7 & 8 & $9 / 10$ \\
\hline 1. Gender & 0.47 & 0.50 & - & & & & & & & & \\
Motivational predictors & & & & & & & & & & \\
$\quad$ 2. Utility value & 4.56 & 1.22 & -0.03 & - & & & & & & \\
$\quad$ 3. Self-efficacy & 4.80 & 1.07 & 0.02 & $.37^{* *}$ & - & & & & & \\
$\quad$ 4. Intrinsic reasons & 5.08 & 1.27 & 0.01 & $.36^{* *}$ & $.39^{* *}$ & - & & & & \\
$\quad$ 5. Self-worth concerns & 4.61 & 1.98 & 0.03 & $.17^{* *}$ & $.11^{* *}$ & .03 & - & & & & \\
Motivational correlates & & & & & & & & & & & \\
$\quad$ 6. Effort regulation & 3.88 & 1.32 & 0.03 & $.28^{* *}$ & $.31^{* *}$ & $.24^{* *}$ & $.14^{* *}$ & - & & & \\
7. Rehearsal & 4.16 & 1.39 & -0.03 & $.33^{* *}$ & $.31^{* *}$ & $.23^{* *}$ & $.33^{* *}$ & $.49^{* *}$ & - & & \\
8. Critical thinking & 4.39 & 1.30 & -0.01 & $.30^{* *}$ & $.32^{* *}$ & $.43^{* *}$ & .04 & $.25^{* *}$ & $.35^{* *}$ & - & - \\
9. Metacognitive regulation & 4.46 & 0.96 & -0.01 & $.41^{* *}$ & $.39^{* *}$ & $.40^{* *}$ & $.22^{* *}$ & $.56^{* *}$ & $.70^{* *}$ & $.54^{* *}$ & \\
10. Test anxiety & 4.18 & 1.38 & -0.02 & $.08^{* *}$ & $-.23^{* *}$ & $-.08^{*}$ & $.36^{* *}$ & -0.02 & $.22^{* *}$ & -0.01 & $.12^{* *}$ \\
\hline
\end{tabular}

Note. ${ }^{*} p<.05,{ }^{* *} p<.01$. Gender was dummy-coded as $0=$ female; $1=$ male.

statements implying students' experience of psychological pressure to succeed (or not fail) can be found at the online supplementary material (Table S2, also Tables S3a-S3c present the statements denoting interviewees' attitudes towards utility value, self-efficacy and intrinsic reasons and Tables S4a-S4b present learning strategies).

\section{Preliminary quantitative analyses}

Table 1 provides the means, standard deviations and bivariate correlations of the variables of the study. As can be noticed, gender was unrelated to the other variables, while most of the other correlations were in line with our expectations. A similar pattern was found for the three subgroups (i.e. past repeaters, current repeaters and nonrepeaters-see online supplemental materials, Tables $\mathrm{S} 5 \mathrm{a}-\mathrm{S} 5 \mathrm{c})$. Preliminary analyses showed that the test of MCAR was statistically significant $\left(\chi^{2}[53]=100.62, p<.001\right)$, suggesting that the few missing (i.e. $<5 \%$ ) may not be at random. Nevertheless, the supplementary analyses showed that the results reported below would have remained virtually unchanged, had we imputed the missing data with the ExpectationMaximization algorithm instead of the listwise deletion approach that we endorsed.

\section{Regression analyses}

Table 2 presents the results of the hierarchical regression analysis (i.e. F-statistic, $B$ values with their standard errors, beta coefficients, as well as effects sizes) for the dependent variables as predicted by gender, group status (i.e. non-repeaters, pastrepeaters, and current-repeaters), utility value, and self-efficacy in Step 1 (upper panel). Utility value and self-efficacy positively predicted effort regulation, rehearsal, critical thinking and meta-cognitive regulation. Also, in line with our hypothesis, utility value positively predicted and self-efficacy negatively predicted test anxiety. Further, compared to students who never repeated the same course level, students who either currently repeated $(\beta=0.10, p<.01)$ or previously repeated $(\beta=0.18, p<.01)$ the course level reported more test anxiety. In addition, past-repeaters were found to report more rehearsal than non-repeaters $(\beta=0.12, p<.01)$. No statistically significant interaction was found in Step 1 between utility value and self-efficacy for any of the five 


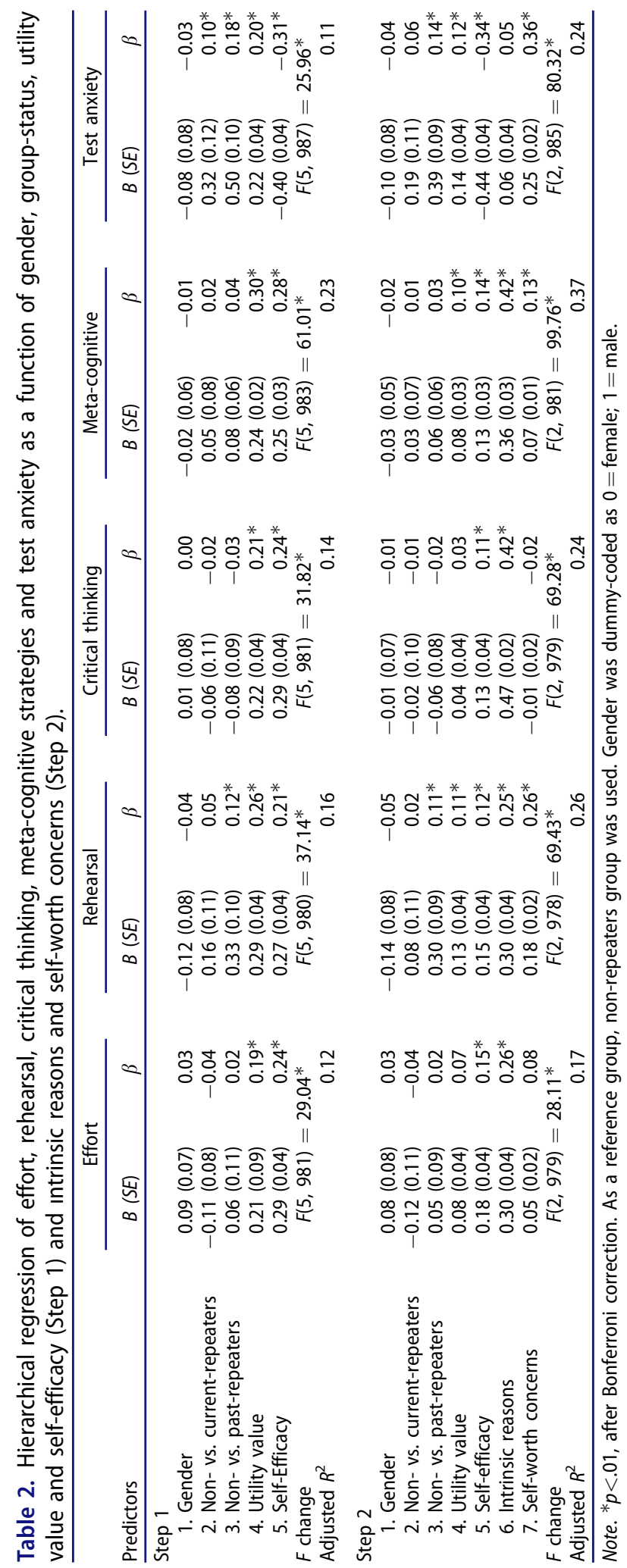


dependent variables. The same was true for the interactions between either utility value or self-efficacy and students' group status. The latter finding suggests that the relation of utility value or self-efficacy to the dependent variables was similar across all students, irrespective of whether they repeated a level at some point in time (currently or previously) or not.

When intrinsic reasons and self-worth concerns were added as predictors in the next Step (see Table 2, lower panel), intrinsic reasons emerged as the most consistent predictor of effort regulation and learning strategies. Self-worth concerns yielded a mixed pattern as they positively predicted rehearsal, meta-cognitive regulation, test anxiety, but not effort regulation and critical thinking. As can be also seen in Table 2, inclusion of intrinsic reasons (and self-worth concerns) attenuated the positive relation of utility value and self-efficacy to effort regulation and learning strategies and rendered the relation between utility value and effort regulation and critical thinking nonsignificant.

Notably, a statistically significant interaction between intrinsic reasons and selfworth concerns (not shown in Table 2) emerged for critical thinking $(B=-0.03$, $S E=0.02, \quad p=.029, \quad \beta=-0.06)$ and meta-cognitive regulation $(B=-0.03, S E=0.01$, $p<.01, \beta=-0.07$ ). A test of simple slopes indicated that the positive relation of intrinsic reasons to critical thinking and meta-cognitive regulation was stronger when students reported low levels of self-worth concerns (respectively, $B=0.61, S E=0.04$, $t=14.74, p<.01$ and $B=0.51, S E=0.03, t=17.84, p<.01)$ than when they reported high levels of self-worth concerns (respectively, $B=0.48, S E=0.05, t=10.63, p<.01$ and $B=0.40, S E=0.03, t=12.92, p<.01)$. These findings suggest that students reported that they used more critical thinking and meta-cognitive regulation if they studied for intrinsic reasons and were freed from any self-worth concerns.

As for the group differences in Step 2, no systematic differences were found either in the mean levels of the dependent variables or the interactions with the other predictors. Specifically, it was found that past-repeaters reported more rehearsal and test anxiety than non-repeaters. Finally, the only statistically significant interaction that was found (not shown in Table 2) concerned the interaction between intrinsic reasons and the group comparison between non-repeaters and past-repeaters in the prediction of rehearsal $(B=0.15, S E=0.07, p=.023, \beta=0.09)$. A test of simple slopes indicated that intrinsic reasons were stronger positive predictors of rehearsal among past-repeaters $(B=0.38, S E=0.06, t=6.96, p<.01)$ than non-repeaters $(B=0.23, S E=0.05, t=4.39$, $p<.01)$. Separate regression analyses for each group and for each dependent variable are available online as a supplementary material (Tables S6a-S6e).

\section{Discussion}

In this study, we examined through a series of hierarchical regression analysis to what extent intrinsic reasons and self-worth-concerns would explain over and above utility value and self-efficacy variation in study efforts (effort regulation), surface (rehearsal) and deep-level learning strategies (critical thinking and meta-cognitive regulation) and affective reactions (test anxiety). More importantly, we examined these associations among university students who, as the semi-structured interviews suggest, 
experienced a psychological pressure to pass their end-of-course tests, given that these tests determined whether students would progress to the next level. Moreover, we tested our hypotheses not only in our entire sample, but also in three distinct groups that might substantially differ in terms of the experienced psychological pressure.

\section{The role of self-efficacy beliefs and utility value}

Congurent with Expectancy-Value theory (Eccles \& Wigfield, 2002), our study indicated that students who placed high value on learning tasks and held self-efficacy beliefs were more likely to report the use of rehearsal, critical thinking and meta-cognitive self-regulation strategies (Liem et al., 2008; Schunk, 2005). More importantly, the associations of utility value and self-efficacy to effort regulation, learning strategies, and test anxiety were found to hold true across all the groups (the only exception concerned the relation of utility value and test anxiety in the 'current-repeaters' group).

Research has shown that valuing plays an important role in academic behaviour in learning the language and affects students' choice of activities which in turn affects effort and persistence (Eccles et al., 1983; Wigfield \& Eccles, 2002) and that students who place high value on tasks and regulate their effort use more deep-level learning strategies (Wigfield \& Eccles, 2002). Lens et al. (2002) showed that students who perceived course material as more instrumental for their future success engaged in more deep-level learning strategies than those who perceived course material as less instrumental. How likely, however, are students who failed in some critical tests a couple of times, and thus may be discouraged from attaching a value to learning English or may start questioning their confidence in language learning, to stop using effective learning strategies? Not so likely, as the findings of this study suggest. Even in educational settings where pressure to succeed culminates, it is, therefore, important to engage students in tasks that are relevant and that bear meaning for their present and future studies. Otherwise, the students might ask questions such as 'Why do we have to do this?'; 'What is the purpose of this?' questioning the value of the tasks (Pintrich \& De Groot, 1990) and eventually quitting.

As for self-efficacy, its associations with effort regulation, learning strategies, and test anxiety was found to hold true across all the groups. Support for this finding also comes from other research (Pajares \& Schunk, 2001) which shows that students who are highly efficacious use more cognitive, metacognitive and resource management (i.e. effort regulation) strategies, and persist longer at a task than those who do not use such strategies (Coutinho, 2008). Further, students with high self-efficacy tend to set higher personal goals and stay motivated even if they face failure (Pajares, 1996). Those with low-self efficacy, on the other hand, judge themselves as failures and undermine their competence by focussing on their failures (Bandura, 1986).

The negative association between self-efficacy and test anxiety, across all three groups, is consistent with the view that those students who believe in their capabilities can better regulate their learning strategies (Bandura, 1986). Meece et al. (1990) showed that students with low self-efficacy beliefs tend to be more anxious in their learning process. The result of this study suggests that students believe that their 
efforts will result in positive outcomes if they put the right amount of effort into studying.

\section{Intrinsic reasons and self-worth concerns}

When intrinsic reasons and self-worth concerns were taken into account, intrinsic reasons emerged as the single, consistent, and stronger positive predictor of effort regulation and learning strategies across three groups. These findings are in full line with the SDT (Ryan \& Deci, 2017) and extend relevant empirical research (e.g. Vansteenkiste et al., 2005) as they underscore the key role that intrinsic reasons can play even in settings where the psychological pressure to succeed (or not fail) is rather high. It also complements previous research findings, based on achievement goal perspective (Elliot, 2005), showing that intrinsic reasons for learning can make a difference (Dompnier et al., 2009; Michou et al., 2014) and serve as reasons that motivate recruitment of effective learning strategies. Research based on achievement goal perspective reveals the existence of a pattern regarding the relation between autonomous reasons, underlying the pursuit of mastery achievement goal, and both surface and deep learning strategies (Elliot \& McGregor, 2001).

Furthermore, the test of simple slopes revealed that deep-learning strategies such as critical thinking and meta-cognitive regulation may be even higher not only when intrinsic reasons are high but also when, at the same time, self-worth concerns are low. This suggests that students with intrinsic reasons benefit more not only when they pursue their educational goals for intrinsic reasons but also when they set aside any self-worth concerns.

In contrast to intrinsic reasons, self-worth concerns predicted test anxiety, while they were unrelated to critical thinking. This finding is in line with SDT (Ryan \& Deci, 2017) which claims that students acting under internal psychological pressure - one of which entails to prove their self-worth - are more likely to experience test anxiety (Lawrence \& Williams, 2013) and to use ineffective learning strategies (Vermetten et al., 2001). Apparently, this is because students who are more focussed on protecting their ego are more likely to direct their resources towards what is needed to conserve their self-esteem. As such, they may be less likely to engage in effective learning strategies. It should be noted, however, that self-worth concerns positively predicted metacognitive regulation, a finding which was in contrast to our original hypothesis. A likely explanation might lie in the way the curriculum is organised in many preparatory schools in that students are encouraged to use meta-cognitive regulation strategies when they study. Thus, those students with heightened self-worth concerns may

report the conscious use of meta-cognitive strategies as they consider it to be expected of them.

Further, the fact that self-worth concerns predicted rehearsal comes as no surprise. It is important for the student to have sufficient surface knowledge before moving to deeper levels of learning. A possible explanation could be that the exam contains specific vocabulary and grammar items which the students may study by mere memorisation. That is, students may favour rehearsal over deep-level strategies. They might emphasise repetition because recalling important information is the key for readily 
showing success in the exams. In doing so, they may ignore the important role of consolidating and extending on the rehearsed information.

\section{Qualitative findings - what the students say about their study experience}

From the semi-structured interviews, we noted that the students in the focus group admitted, either implicitly or explicitly, that they were under psychological pressure to succeed (or not fail) in the upcoming exams. Notably, this pressure was expressed not only from students who had previously or currently failed but also from those who experienced no failure up to that date. All the interviewees appeared to agree that, yes, 'there [was] a lot of stress because of the [exams],' with some of them blaming themselves for their failure, others blaming the demanding context, and others criticising their parents for not understanding the challenges in language learning. The following concern was made by a student who blamed herself for failure:

I cannot attribute my success or failure to anyone else than me. I know I should study to pass [.... I attribute my failure to myself. I know myself $[\ldots]$ I am unsuccessful because I do not do what is expected of me.

From the attribution theory perspective (Weiner, 1985), attributing one's failure to lack of effort seems an adaptive approach as it ascribes the causes of an outcome to internal and controllable factor (i.e. one's own efforts). However, when students experience repeated failure, they may turn from internal and controllable attributions to either internal uncontrollable (i.e. lack of ability) or to external uncontrollable ones (e.g. difficulty of the course) in an attempt to preserve their sense of self-worth (Perry et al., 2005).

Obviously, the teacher can play a vital role in reverting such situations, thereby emphasising to the learners the importance of proactively regulating their own learning. Certainly, teachers should design learning activities which will carry some practical meaning for their students - for instance by drawing links between the covered material and students' future studies, or careers.

\section{Limitations}

Regarding limitations, no causal inferences can be claimed, given the cross-sectional design. It is possible that prior success or failure may dictate the learning strategies the students employ which ultimately may determine the reasons for studying, the utility value, and self-efficacy beliefs. Convenience sampling may pose a threat to the generalizability of results in that both quantitative and qualitative results of the study are limited to the private language preparatory programme the researcher is working in. Thus, generalising the present findings to other preparatory programmes of other universities - let alone to different educational systems and cultures - should be made with caution. Although consent was sought from the students who voluntarily took part in the semi-structured interview, individual students might have felt the need to justify their answers. The students' tendency to do so may be considered a possible limitation, too. Future scholars might want to uncover through more rigorous and extended qualitative research (e.g. content analysis through interviews) the 
relation of utility value, self-efficacy, intrinsic reasons, and self-worth concerns to learning strategies. A further limitation concerns the low alpha for utility value, intrinsic reasons and effort regulation, something which might have obscured the possibility to detect in a more rigorous way the presence of statistically significant differences in the relations between our hypothesised predictors and the dependent variables across the three sub-groups (i.e. past-repeaters, current-repeaters, and non-repeaters). Finally, it should be acknowledged that a more proper analytical approach would require multilevel analysis through which shared variance due to students' classroom membership could be statistically controlled for. In that way, we would have been able to control for any extraneous variance (mainly due to shared variance) and thus further increase our statistical power to uncover the relations lying at the population. Unfortunately, however, we were unable to analyse our data under the multilevel framework because during data collection, we omitted asking students about their classroom membership.

\section{Conclusion}

In line with the expectancy-value theory, we found that utility value and self-efficacy positively predicted effort regulation, rehearsal, critical thinking and meta-cognitive self-regulation. More importantly, however, we found, in line with the SDT (Ryan \& Deci, 2017), that intrinsic reasons for studying was the most consistent, positive, predictor of these outcomes, even in the group of students who were under psychological pressure to succeed (or not fail again).

\section{Acknowledgments}

We would like to thank Assistant Professor Jennie Farber Lane for her support.

\section{Disclosure statement}

No potential conflict of interest was reported by the author(s).

\section{ORCID}

Ayça Üner (ID http://orcid.org/0000-0002-5255-9936

Athanasios Mouratidis (D) http://orcid.org/0000-0003-0325-8077

ilker Kalender (iD http://orcid.org/0000-0003-1282-4149

\section{References}

Bandura, A. (1986). Social foundations of thought and action: A social cognitive theory. PrenticeHall, Inc.

Bathgate, M., \& Schunn, C. (2017). Factors that deepen or attenuate decline of science utility value during the middle school years. Contemporary Educational Psychology, 49, 215-225. 10. 1016/j.cedpsych.2017.02.005 
Benoit, K., Watanabe, K., Wang, H., Nulty, P., Obeng, A., Müller, S., \& Matsuo, A. (2018). Quanteda: An R package for the quantitative analysis of textual data. Journal of Open Source Software, 3(30), 774-778. 10.21105/joss.00774

Bonaccio, S., \& Reeve, C. (2010). The nature and relative importance of students' perceptions of the sources of test anxiety. Learning and Individual Differences, 20(6), 617-625. 10.1016/j.lindif. 2010.09.007

Braun, V., \& Clarke, V. (2006). Using thematic analysis in psychology. Qualitative Research in Psychology, 3(2), 77-101. 10.1191/1478088706qp063oa.

Chou, M. H. (2018). Predicting self-efficacy in test preparation: Gender, value, anxiety, test performance, and strategies. The Journal of Educational Research, Advance Online Publication. 112(1), 61-71. 10.1080/00220671.2018.1437530

Cohen, J., Cohen, P., West, S. G., \& Aiken, L. S. (2003). Applied multiple regression analysis for the behavioral sciences (3rd ed.). Lawrence Erlbaum.

Coutinho, S. (2008). Self-efficacy, metacognition, and performance. North American Journal of Psychology, 10(1), 165-172.

Credé, M., \& Phillips, L. A. (2011). A meta-analytic review of the motivated strategies for learning questionnaire. Learning and Individual Differences, 21(4), 337-346. 10.1016/j.lindif.2011.03.002

Creswell, J., \& Plano Clark, V. (2007). Designing and conducting mixed methods research. Sage.

Dompnier, B., Darnon, C., \& Butera, F. (2009). Faking the desire to learn: A clarification of the link between mastery goals and academic achievement. Psychological Science, 20(8), 939-943. $10.1111 / j .1467-9280.2009 .02384 . x$

Dörnyei, Z. (2002). The motivational basis of language learning tasks. In P. Robinson (Ed.), Individual differences and instructed language learning (Vol. 2, pp. 137-158). John Benjamins.

Drysdale, M., \& McBeath, M. (2018). Motivation, self-efficacy and learning strategies of university students participating in work-integrated learning. Journal of Education and Work, 31(5-6), 478-488. 10.1080/13639080.2018.1533240

Durik, A. M., \& Harackiewicz, J. M. (2007). Different strokes for different folks: How individual interest moderates the effects of situational factors on task interest. Journal of Educational Psychology, 99(3), 597-610. 10.1037/0022-0663.99.3.597

Eccles, J. S., Adler, T. F., Futterman, R., Goff, S. B., Kaczala, C. M., Meece, J. L., \& Midgley, C. (1983). Expectancies, values, and academic behaviors. In J. T. Spence (Ed.) Achievement and achievement motivation (pp. 75-146). W. H. Freeman.

Eccles, J., \& Wigfield, A. (2002). Motivational beliefs, values and goals. Annual Review of Psychology, 53(1), 109-132. 10.1146/annurev.psych.53.100901.135153

Elliot, A. J. (2005). A conceptual history of the achievement goal construct. In A. J. Elliot \& C. S. Dweck (Eds.), Handbook of competence and motivation (pp. 52-72). Guilford.

Elliot, A. J., \& McGregor, H. A. (2001). A $2 \times 2$ achievement goal framework. Journal of Personality and Social Psychology, 80(3), 501-971. 10.1037/0022-3514.80.3.501

Folkman, S., Lazarus, R. S., Dunkel-Schetter, C., DeLongis, A., \& Gruen, R. J. (1986). Dynamics of a stressful encounter - cognitive appraisal, coping, and encounter outcomes. Journal of Personality and Social Psychology, 50(5), 992-1003. 10.1037/0022-3514.50.5.992

Garcia, T., \& Pintrich, P. R. (1994). Regulating motivation and cognition in the classroom: The role of self-schemas and self-regulatory strategies. In D. H. Schunk \& B. J. Zimmerman (Eds.), Motivation and classroom learning, self-regulation of learning and performance: Issues and educational applications (pp. 127-153). Erlbaum.

Grant, H., \& Dweck, C. S. (2003). Clarifying achievement goals and their impact. Journal of Personality and Social Psychology, 85(3), 541-553. 10.1037/0022-3514.85.3.541

Halonen, J. S. (1995). Demystifying critical thinking. Teaching of Psychology, 22(1), 75-81. 10. 1207/s15328023top2201_23

Hill, M. R., Goicochea, S., \& Merlo, L. J. (2018). In their own words: Stressors facing medical students in the millennial generation. Medical Education Online, 23(1), 1-10. 10.1080/10872981. 20181530558. 
Komarraju, M., \& Nadler, D. (2013). Self-efficacy and academic achievement: Why do implicit beliefs, goals, and effort regulation matter? Learning and Individual Differences, 25, 67-72. 10. 1016/j.lindif.2013.01.005

Lawrence, J., \& Williams, A. (2013). Anxiety explains why people with domain-contingent selfworth underperform on ability-diagnostic tests. Journal of Research in Personality, 47(3), 227-232. 10.1016/j.jrp.2013.01.004

Lens, W., Simons, J., \& Dewitte, S. (2002). From duty to desire: The role of students' future time perspective and instrumentality perceptions for study motivation and self-regulation. In $\mathrm{F}$. Pajares \& T. Urdan (Eds.), Academic motivation of adolescents (pp. 221-245). Information Age Publishing.

León, J., Núñez, J. L., \& Liew, J. (2015). Self-determination and stem education: Effects of autonomy, motivation, and self-regulated learning on high school math achievement. Learning and Individual Differences, 43, 156-163. 10.1016/j.lindif.2015.08.017.

Lepper, M. R., Corpus, J. H., \& lyengar, S. S. (2005). Intrinsic and extrinsic motivational orientations in the classroom: Age differences and academic correlates. Journal of Educational Psychology, 97(2), 184-196. 10.1037/0022-0663.97.2.184

Liem, A. D., Lau, S., \& Nie, Y. (2008). The role of self-efficacy, task value, and achievement goals in predicting learning strategies, task disengagement, peer relationship, and achievement outcome. Contemporary Educational Psychology, 33(4), 486-512. 10.1016/j.cedpsych.2007.08.001

Meece, J. L., Wigfield, A., \& Eccles, J. S. (1990). Predictors of math anxiety and its influence on young adolescents' course enrollment intentions and performance in mathematics. Journal of Educational Psychology, 82(1), 60-70. 10.1037/0022-0663.82.1.60.

Michou, A., Vansteenkiste, M., Mouratidis, A., \& Lens, W. (2014). Enriching the hierarchical model of achievement motivation: Autonomous and controlling reasons underlying achievement goals. British Journal of Educational Psychology, 84(4), 650-666. 10.1111/bjep.12055

Mouratidis, A., Michou, A., Aelterman, N., Haerens, L., \& Vansteenkiste, M. (2018). Begin-ofschool-year perceived autonomy-support and structure as predictors of end-of-school-year study efforts and procrastination: The mediating role of autonomous and controlled motivation. Educational Psychology, 38(4), 435-450. 10.1080/01443410.2017.1402863

Noels, K. A., Pelletier, L., Clément, R., \& Vallerand, R. (2000). Why are you learning a second language? Motivational orientations and self-determination theory. Language Learning, 50(1), 57-85. 10.1111/0023-8333.00111

Pajares, F. (1996). Self-efficacy beliefs in academic settings. Review of Educational Research, 66(4), 543-578. 10.3102/00346543066004543.

Pajares, F., \& Schunk, D. H. (2001). Self-beliefs and school success: Self-efficacy, self-concept, and school achievement. Perception, 11, 239-266.

Perry, R. P., Hall, N. C., \& Ruthig, J. C. (2005). Perceived (academic) control and scholastic attainment in higher education. In J. C. Smart (Ed.). Higher education: Handbook of theory and research (pp. 363-436). Springer.

Pintrich, P. R. (2000). An achievement goal theory perspective on issues in motivation terminology, theory, and research. Contemporary Educational Psychology, 25(1), 92-104. 10.1006/ ceps.1999.1017

Pintrich, P. R., \& De Groot, E. V. (1990). Motivational and self-regulated learning components of classroom academic performance. Journal of Educational Psychology, 82(1), 33-40. 10.1037/ 0022-0663.82.1.33

Pintrich, P. R., \& Garcia, T. (1991). Student goal orientation and self-regulation in the college classroom. In M. L. Maehr \& P. R. Pintrich (Eds.), Advances in motivation and achievement: Goals and self-regulatory processes (Vol. 7, pp. 371-402). JAI Press.

Putwain, D. W., \& Daly, A. L. (2013). Do clusters of test anxiety and academic buoyancy differentially predict academic performance? Learning and Individual Differences, 27, 157-162. 10. 1016/j.lindif.2013.07.010

R Core Team. (2018). R 3.5.0: A language and environment for statistical computing. R Foundation for Statistical Computing. http://www.R-project.org/. 
Richardson, M., Abraham, C., \& Bond, R. (2012). Psychological correlates of university students' academic performance: A systematic review and meta-analysis. Psychological Bulletin, 138(2), 353-387. 10.1037/a0026838

Roick, J., \& Ringeisen, T. (2017). Self-efficacy, test anxiety, and academic success: A longitudinal validation. International Journal of Educational Research, 83, 84-93. 10.1016/j.ijer.2016.12.006

Ryan, R. M., \& Deci, E. L. (2017). Self-determination theory: Basic psychological needs in motivation, development, and wellness. The Guilford Press.

Schunk, D. H. (2005). Self-regulated learning: The educational legacy of Paul R. Pintrich. Educational Psychologist, 40(2), 85-94. 10.1207/s15326985ep4002_3

Tuominen-Soini, H., \& Salmela-Aro, K. (2014). Schoolwork engagement and burnout among Finnish high school students and young adults: Profiles, progressions, and educational outcomes. Developmental Psychology, 50(3), 649-662. 10.1037/a0033898

Vansteenkiste, M., Lens, W., Elliot, A., Soenens, B., \& Mouratidis, A. (2014). Moving the achievement goal approach one step forward: toward a systematic examination of the autonomous and controlled reasons underlying achievement goals. Educational Psychologist, 49(3), 153-174. 10.1080/00461520.2014.928598

Vansteenkiste, M., Niemiec, C., \& Soenens, B. (2010). The development of the five mini theories of self-determination theory: An historical overview, emerging trends, and future directions. In T. Urdan \& S. Karabenick (Eds.), The decade ahead: Theoretical perspectives on motivation and achievement (Vol. 16, pp. 105-165). Emerald.

Vansteenkiste, M., Simons, J., Lens, W., Soenens, B., \& Matos, L. (2005). Examining the motivational impact of intrinsic versus extrinsic goal framing and autonomy-supportive versus internally controlling communication style on early adolescents' academic achievement. Child Development, 76(2), 483-501. 10.1111/j.1467-8624.2005.00858.x.

Vansteenkiste, M., Smeets, S., Soenens, B., Lens, W., Matos, L., \& Deci, E. L. (2010). Autonomous and controlled regulation of performance-approach goals: Their relations to perfectionism and educational outcomes. Motivation and Emotion, 34(4), 333-353. 10.1007/s11031-010-91883.

Vermetten, Y. J., Lodewijks, H. G., \& Vermunt, J. D. (2001). The role of personality traits and goal orientations in strategy use. Contemporary Educational Psychology, 26(2), 149-170. 10.1006/ ceps.1999.1042.

Weiner, B. (1985). An attributional theory of achievement motivation and emotion. Psychological Review, 92(4), 548-573. 10.1037//0033-295x.92.4.548

Welbers, K., Van Atteveldt, W., \& Benoit, K. (2017). Text Analysis in R. Communication Methods and Measures, 11(4), 245-265. 10.1080/19312458.2017.1387238

Wigfield, A., \& Eccles, J. S. (2002). The development of competence beliefs, expectancies for success, and achievement values from childhood to adolescence. In A. Wigfield \& J. S. Eccles (Eds.), Development of achievement motivation (pp. 91-120). Academic Press.

Zimmerman, B. J. (2000). Attaining self-regulation: A social cognitive perspective. In M. Boekaerts, P. R. Pintrich and M. Zeidner (Eds.), Handbook of self-regulation (pp. 13). Academic Press. 